\title{
DISASTER PREVENTION COASTAL MAP PRODUCTION BY MMS \& C3D
}

\author{
Shuhei HATAKE ${ }^{\mathrm{a}}$, Yuki KOHORI ${ }^{\mathrm{a} *}$, Yasushi.WATANABE ${ }^{\mathrm{b} *}$ \\ a Asia Air Survey, Geospatial Information Division , 2150004 Kawawaki, Kanagawa, Japan- (sh.hatake, yuk.kohori)@ajiko.co.jp \\ ${ }^{\mathrm{b}}$ Arc Geo Support, Osaka branch, Chuou-ku, Osaka, Japan- watanabe@a-gs.jp
}

Commission ICWGI/Va - Mobile Scanning and Imaging Systems for 3D Surveying and Mapping

KEY WORDS: Coastal Mapping, Tsunami, MMS, Interferometry echo sounder, continuous topography

\begin{abstract}
:
In March 2011, Eastern Japan suffered serious damage of Tsunami caused by a massive earthquake. In 2012, Ministry of Land, Infrastructure and Transport published "Guideline of setting assumed areas of inundation by Tsunami" to establish the conditions of topography data used for simulation of Tsunami. In this guideline, the elevation data prepared by Geographical Survey Institute of Japan and $2 \mathrm{~m} / 5 \mathrm{~m} / 10 \mathrm{~m}$ mesh data of NSDI are adopted for land area, while 500m mesh data of Hydrographic and Oceanographic Department of Japan Coast Guard and sea charts are adopted for water area. These data, however, do not have continuity between land area and water area. Therefore, in order to study the possibility of providing information for coastal disaster prevention, we have developed an efficient method to acquire continuous topography over land and water including tidal zone. Land area data are collected by Mobile Mapping System (MMS) and water area depth data are collected by interferometry echo sounder (C3D), and both data are simultaneously acquired on a same boat. Elaborate point cloud data of $1 \mathrm{~m}$ or smaller are expected to be used for realistic simulation of Tsunami waves going upstream around shoreline. Tests were made in Tokyo Bay (in 2014) and Osaka Bay (in 2015). The purpose the test in Osaka Bay is to make coastal map for disaster prevention as a countermeasure for predicted Nankai massive earthquake. In addition to Tsunami simulation, the continuous data covering land and marine areas are expected to be used effectively for maintenance and repair of aged port and river facilities, maintenance and investigation of dykes, and ecosystem preservation.
\end{abstract}

\section{PREFACE}

Japan is an archipelago subject to natural disasters like earthquakes, tsunamis, volcanic eruptions and typhoons and one of the most severely disaster-affected countries in the world. Particularly on March 11 2011, the tsunami of the Great East Japan Earthquake of magnitude of 9.0 caused unprecedented damage on the Pacific coast of eastern Japan. In 2012, Ministry of Land, Infrastructure and Transport issued "Guideline of setting assumed areas inundated by Tsunami". It contains the use of topographic data of land and water areas to calculate simulation of the inundation and to estimate the damage by inundation.

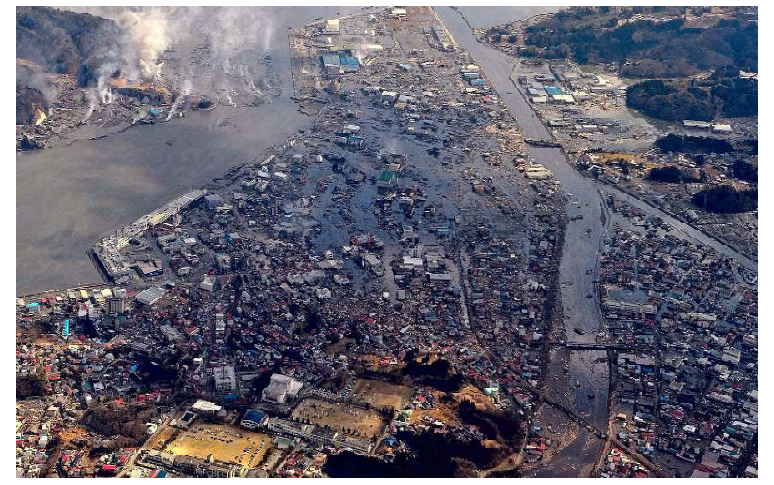

Figure 1. Immediately after the Great East Japan Earthquake (Near Kesenuma, Miyagi Pref.)
Currently digital elevation model of $2 \mathrm{~m} / 5 \mathrm{~m} / 10 \mathrm{~m}$ mesh data prepared by Geospatial Information Authority of Japan are used for land area, while 500m mesh seabed topography data of Japan Coast Guard are used for water area.

Surface measurement by topographic LiDAR or narrow multi-beam echo sounder cannot secure continuity of the water edge data in land and water areas because water edge (near shoreline) is in blind spot.

In view of the situation, we verified a method to acquire efficiently and accurately continuous water edge topographic data over land and water including intertidal zone. In this method, land area data were collected by Mobile Mapping System (MMS) and water area data were collected by Interferometry Echo-Sounder (C3D), and these two measuring devices were installed together on the same vessel to acquire the data simultaneously. The data thus acquired are 3D seamless topography of land and water areas and denominated in this study as "Disaster Prevention Coastal Map". Because the map has elaborate data of point cloud with density of 100 points/m2 or more, detailed topography and shapes of structures can be recognized and it can be used for simulation of inundation by tsunami and for maintenance of embankments, structures and other public facilities as well.

\footnotetext{
*Corresponding author
} 


\section{VERIFICATION TEST}

The system is intended for the anticipated area of devastation by the Nankai Trough Earthquake, predicted to occur within 30 years to come with probability of 70 percent. In December 2015, the verification test was made at Kishiwada Port, one of the important ports in western Japan that is anticipated to suffer severe damage by tsunami. This port has various structures like water gates, highway bridges and embankments and is suitable to see how the system can be used to check these public facilities.

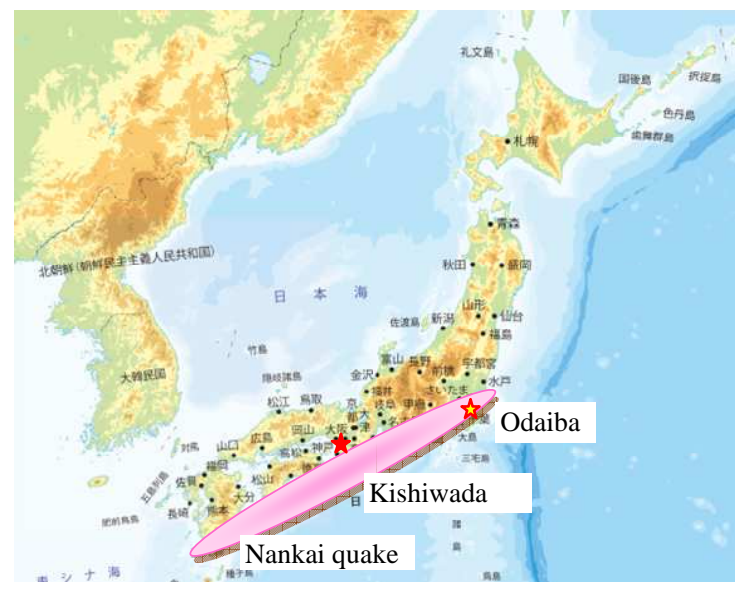

Figure 2. Damage Estimation area of the Nankai Trough Earthquake and Experimental location

Before the tests at Kishiwada, similar tests had been made at Odaiba in Tokyo Bay in April 2014, and the following two problems were found.

- Horizontal position errors caused by difference of positioning devices in land and water areas

- Areas not measured (blank areas) in intertidal zones due to installation of positioning devices

These problems were taken into consideration for constructing the system for testing at Kishiwada.

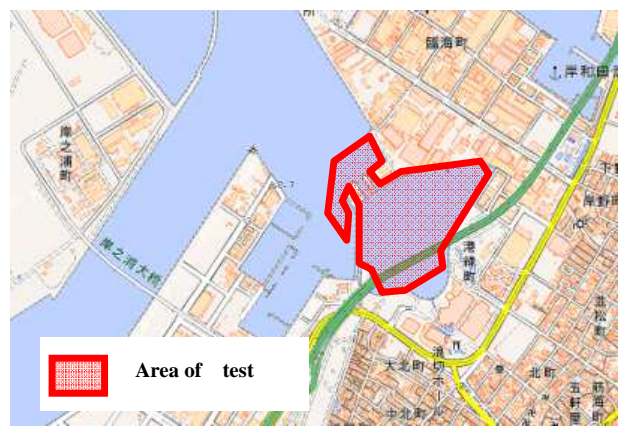

Figure. 3. Verification test site (Kishiwada Port in Osaka)
The system adopted at Kishiwada is similar to the one used at Odaiba in 2014. Table 1. shows the specification of the system and Figure. 4 show how it was installed. It is desirous to use positioning devices of the same type in both land and water areas but the integration was impossible. The data acquired, therefore, synchronized with GPS time when processing. Time of PCs was also synchronized to minimize the error caused by different types of equipment.

Table 1. Specification of MMS \& C3D

\begin{tabular}{|c|c|c|}
\hline & & MMS \\
\hline Device & Meker & Various elements \\
\hline \multirow{3}{*}{ GNSS } & \multirow{3}{*}{$\begin{array}{c}\text { NovAtel } \\
\text { GPS-702-GG }\end{array}$} & Channel \\
\hline & & GPSL1:14 GPSL2:14 GPSL5:6 \\
\hline & & GLONASSL1:12 GLONASSL2:12 \\
\hline \multirow{3}{*}{ IMU } & \multirow{3}{*}{$\begin{array}{c}\text { IGI } \\
\text { AEROcontrol-III }\end{array}$} & Acquisition rate $: 400 \mathrm{~Hz}$ \\
\hline & & Accuracy: Heading $0.007^{\circ} \quad$ RMS \\
\hline & & Accuracy: Roll/Pitch $0.003^{\circ}$ RMS \\
\hline \multirow{3}{*}{ Sensor } & \multirow{3}{*}{$\begin{array}{c}\text { RIEGL } \\
\text { VQ-250 }\end{array}$} & Irradiation rate: $200 \mathrm{kHz}$ \\
\hline & & Scan rate: $100 \mathrm{~Hz}$ \\
\hline & & Accuracy: $\pm 10 \mathrm{~mm}$ \\
\hline Camera & $\begin{array}{c}\text { POINT GREY } \\
\text { LadyBug3 }\end{array}$ & resolution: $1600 \times 1200 \times 6$ \\
\hline & & C3D \\
\hline Device & Meker & Various elements \\
\hline \multirow[b]{2}{*}{ GNSS } & \multirow{2}{*}{$\begin{array}{l}\text { Hemisphere } \\
\text { R110 }\end{array}$} & Channel \\
\hline & & GPSL1:12 \\
\hline \multirow{3}{*}{ IMU } & \multirow{3}{*}{$\begin{array}{l}\text { iXSEA } \\
\text { Octans }\end{array}$} & Acquisition rate: $0.1 \sim 200 \mathrm{~Hz}$ \\
\hline & & Accuracy: Heading $0.1^{\circ} \quad$ RMS \\
\hline & & Accuracy: Roll/Pitch $0.01^{\circ}$ RMS \\
\hline \multirow{3}{*}{ Sensor } & \multirow{3}{*}{$\begin{array}{c}\text { Benthos } \\
\text { C3D }\end{array}$} & Frequency: $200 \mathrm{kHz}$ \\
\hline & & Transmission interval:30pings/sec \\
\hline & & Sounding resolution: $5.5 \mathrm{~cm}$ \\
\hline Camera & GoPro & \\
\hline
\end{tabular}

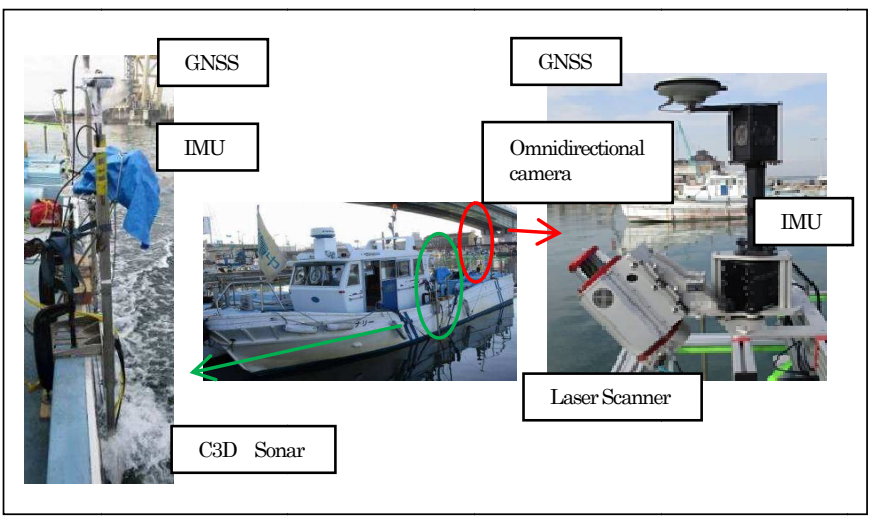

Figure 4. Devices installed

To facilitate data processing after the measuring, C3D was installed on portside and MMS was installed on stern. At these positions, C3D could evade the noise of bubbles created by the wake of the vessel and MMS could keep obstacles like fixture of the vessel out of the measuring area. 
Table 2. Time schedule of the work

\begin{tabular}{|c|l|c|}
\hline & \multicolumn{1}{|c|}{$\begin{array}{c}\text { MMS } \\
2015 / 12 / 14\end{array}$} & $\begin{array}{c}\text { C3D } \\
2015 / 12 / 15\end{array}$ \\
\hline 9:00 12:00 & Installation \\
\hline 13:00 14:00 & Calibration, Test run \\
\hline $14: 00 \sim 17: 00$ & Measurement \\
\hline $17: 00 \sim 17: 30$ & End work/Prepare retreat \\
\hline
\end{tabular}

2 days (including 1 day to spare) were spent to acquire the data. Table 2 shows time schedule of the work. First the vessel was navigated along the coastline in the area to measure and then shuttled in the direction of southwest and then in north east direction to make sure that no section would remain unmeasured in the area.

For correction of depth sounding of C3D, sonic speed was measured before and after the work. The specification of the MMS states that it must be initialized for 5 minutes at $40 \mathrm{~km} / \mathrm{h}$ but the vessel traveling speed is slower. Therefore, an additional GPS was installed on MMS to shorten the initialization time.

\section{DATA PROCESSING}

Figure. 5. shows flow of processing and integration of data of MMS and C3D. After integration with GNSS/IMU and sonic speed correction, errors data like acoustic noise, electrical noise, wakes of fish and ships and bubbles were removed from C3D depth sounding data. Then errors of installation angle of $\mathrm{C} 3 \mathrm{D}$ and IMU (roll/pitch/yaw) were calculated and corrected.

MMS

\begin{tabular}{|c|c|}
\hline \multicolumn{2}{|c|}{ Installation } \\
\hline \multicolumn{2}{|c|}{$\downarrow$} \\
\hline \multicolumn{2}{|c|}{ Measurement } \\
\hline$\downarrow$ & $\downarrow$ \\
\hline GNSS/IMU analysis & GNSS/IMU analysis \\
\hline$\downarrow$ & $\downarrow$ \\
\hline Point cloud calculation & Noise removal \\
\hline$\downarrow$ & $\downarrow$ \\
\hline Noise removal & Point cloud calculation \\
\hline$\downarrow$ & $\downarrow$ \\
\hline \multicolumn{2}{|c|}{ Integration } \\
\hline \multicolumn{2}{|c|}{$\downarrow$} \\
\hline
\end{tabular}

Figure 5. Work flow

When processing MMS data, wakes were created by analyzing GNSS/IMU of post processing kinematic method. Range data were added to the position information thus acquired to calculate $3 \mathrm{D}$ point cloud. Noise of bubbles generated by the screw was also removed. To integrate the data from MMS and C3D, (1) reference elevation of the 3D data is fixed at TP (mean sea surface of Tokyo Bay) and (2) minus signs were added to all elevation of $\mathrm{C} 3 \mathrm{D}$ ( $\mathrm{Z}$ value) for integration.

The integrated data were uploaded on the point cloud viewer, "LaserMapViewer(LMV)" of Asia Air Survey Co. Ltd. LMV can acquire $360^{\circ}$ omnidirectional images and can display them by linking with position information. LMV also has functions to measure, display sections and gradient tints by point cloud data.

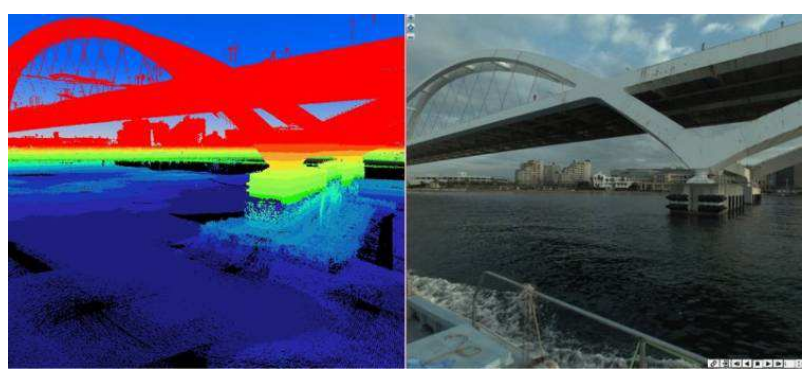

Figure 6. Point cloud of LMV and Omnidirectional image link function

\section{RESULT OF VERIFICATION TESTS}

C3D can acquire detailed seabed topography. Figure 7. shows bathymetry of gradient tints where point cloud of surrounding land is shown in red (left) to compare with aerial ortho photo (right).
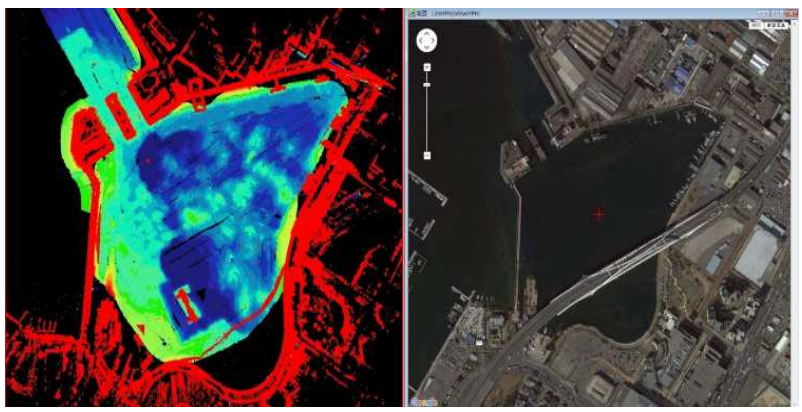

Figure 7. Data acquired by C3D (Left) $\&$ Aerial orthophoto (Right)

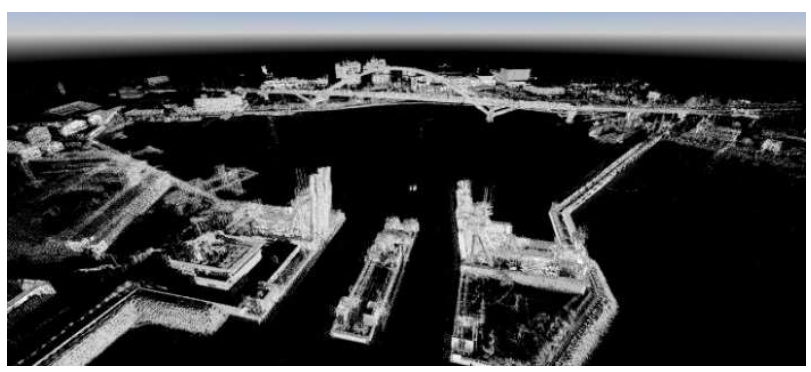

Figure 8 . Recognition of coastal area in point cloud by MMS

Topography and features of the coastal area were acquired 
by MMS because its VQ250 laser measures up to 300m ahead of it. Figure 8. shows group point data acquired in land area where detailed shapes of structures, top surface of embankments and elevation of wave dissipation blocks can be recognized. When the massive earthquake hit east Japan in 2011, damage investigation by land vehicles was impossible because most roads were blocked by debris and cracks (Figure 9). In such a case investigation by boats may be advantageous thanks to their mobility on water.

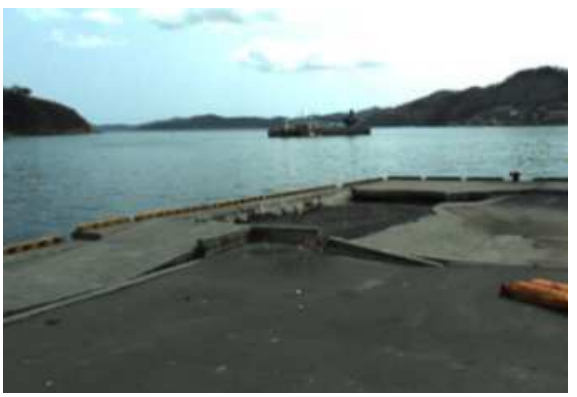

Figure 9. Damaged embankments

(the Great East Japan Earthquake in 2011)

\section{PROBLEMS OF THE SYSTEN YET TO BE SOLVED}

Both MMS and C3D create blank areas due to laser or echo blocked by obstacles.

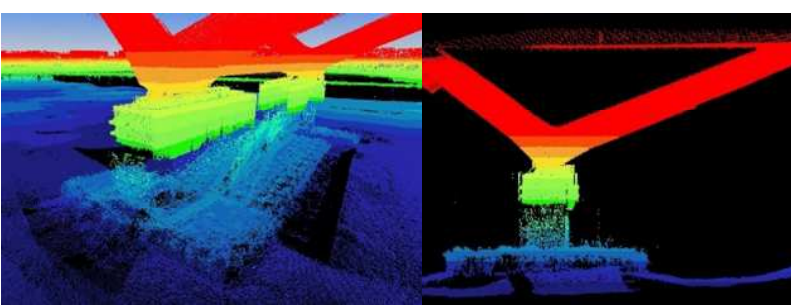

Figure.10. Bridge column (Left) \& its magnified section (Right)

\subsection{Problem of C3D}

Figure 11. shows a blank area of about $2 \mathrm{~m}$ (marked by pink circle) on water edge and another blank area of vertical stripe on seabed (marked in yellow). The former was created due to blocking of echo on convex terrain and the latter was created because nadir depth cannot be acquired by side scanning.

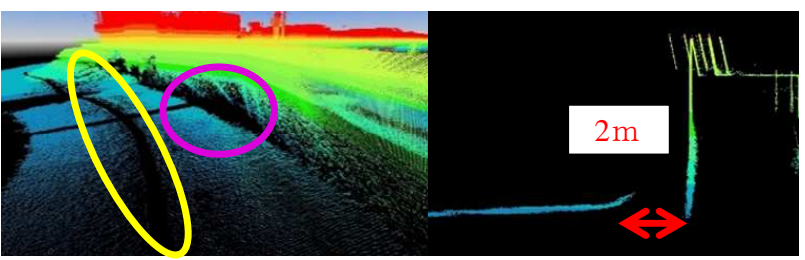

Figure 11. Blank area on seabed

\subsection{Problem of MMS}

Figure 12. shows a blank area because a blind spot was created by a moored boat. Seamless data was not created because $\mathrm{C} 3 \mathrm{D}$ also failed to measure. As shown in Table 3, deviation was created between land and water areas because two positioning devices of different types were used. But this time the deviation was not as big as the tests at Odaiba. Figure 13. shows horizontal position error (MMS in pink and C3D in light blue). GNSS positioning error is shown in Table 4.

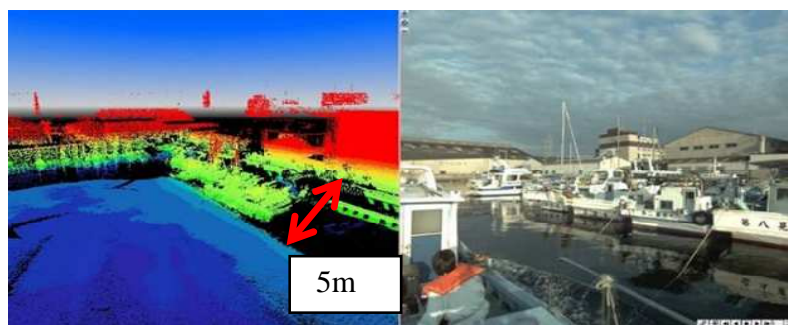

Figure 12. Blank area due to moored boat

Point cloud of LMV are linked with omnidirectional images

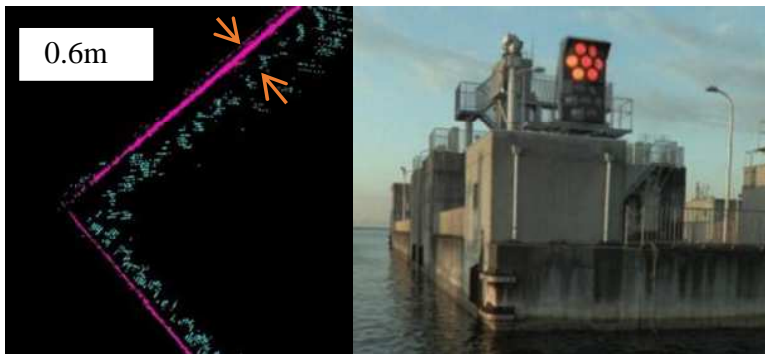

Figure. 13. Horizontal position deviation

Table 3. Horizontal errors in Odaiba and Kishiwada

\begin{tabular}{|l|l|r|}
\hline System & \multicolumn{1}{|c|}{ GNSS Correction method } & Horizontal Error \\
\hline C3D & D-GNSS correction & $1 \sim 7 \mathrm{~m}$ \\
\hline MMS & $\begin{array}{l}\text { Post Processing } \\
\text { Kinematic analysis }\end{array}$ & $0.01 \sim 0.02 \mathrm{~m}$ \\
\hline
\end{tabular}

tests

Table 4. GNSS positioning error

\begin{tabular}{|l|c|c|}
\hline & Odaiba & Kishiwada \\
\hline Horizontal error $(\mathrm{m})$ & 1.04 & 0.6 \\
\hline
\end{tabular}

In view of higher accuracy requested in the future for inspecting various public facilities, it is necessary to integrate GNSS/IMU equipment and establish a system which will not create errors attributable to the system and will acquire the same positioning data. 


\section{APPLICATION OF THE SYSTEM FOR COUNTERMEASURE QUAKE \& TSUNAMI DISASTER}

Central Disaster Prevention Council issued "Nankai Trough Earthquake Disaster Prevention Master Plan” in 2014 which defines the emergency operations for 72 hours after an earthquake;

(1) Emergency transportation route planning

(2)Rescue and fire Figurehting

(3)Medical care

(4) Transportation of supplies

(5) Transportation of fuels

(1) Emergency transportation route is absolutely necessary to carry out the operations of (2) to (5), and above all mass transport of supplies and fuels by ships is important.

The plan gives the first priority to eliminate obstacles on waterways to establish shipping terminals and ensure safe waterways on day 1 ( 24 hours). Study was made on how the findings obtained from the tests will be used for the emergency operations of Nankai Trough Earthquake and the followings were recommended:

- MMS laser data: 3D point cloud (after analysis)

$\rightarrow$ To check collapsed buildings and facilities

- MMS omnidirectional images: Real time images

$\rightarrow$ To check damages on berthing places

- MMS omnidirectional images: Panorama image

$\rightarrow$ To check destroyed port facilities and scattered debris

- C3D sounding data: Underwater live sonar data

$\rightarrow$ To search survivors and missing persons

- C3D sounding data: Seabed topography (after analysis)

$\rightarrow$ To analyze capability of berthing boats and tsunami running upstream.

- C3D sounding data: Seabed topography (after analysis)

$\rightarrow$ To check sunken debris on seabed.

It is advisable to update and maintain the data at normal times and use them

(1) to compare with the data after the disaster,

(2) to improve accuracy of calculating tsunami running upstream and

(3) to recognize actual situation at human eye level.

Table 5 . shows the initial data

Table 5. Data to be prepared at normal times

\begin{tabular}{|l|l|l|l|}
\hline \multicolumn{1}{|c|}{ Data } & \multicolumn{1}{|c|}{ MMS } & \multicolumn{1}{c|}{ C3D } & \multicolumn{1}{c|}{ Note } \\
\hline Topography & $\begin{array}{l}\text { Land point } \\
\text { clouds }\end{array}$ & $\begin{array}{l}\text { bathymetric } \\
\text { point clouds } \\
\text { (depth) }\end{array}$ & $\begin{array}{l}\text { Data of hydrographic survey and } \\
\text { topographic LiDAR are also } \\
\text { acceptable, but they must be } \\
\text { preferably seamless. }\end{array}$ \\
\hline Images & $\begin{array}{l}\text { Omnidirectional } \\
\text { images }\end{array}$ & $\begin{array}{l}\text { Underwater } \\
\text { Camera }\end{array}$ & $\begin{array}{l}\text { Omnidirectional images are used } \\
\text { for creating images at human eye } \\
\text { level. (like Street View of Google) }\end{array}$ \\
\hline
\end{tabular}

Figure. 14. shows the flow of the coastal area disaster prevention system of MMS + C3D at the time of disaster and at normal times. It is imperative to set up time-line so that actions can be taken as per the disaster prevention master plan. The data acquired by this system may be used more quickly and effectively if GIS is prepared linking with the marine cadastre of Japan Coast Guard and tsunami hazard maps.

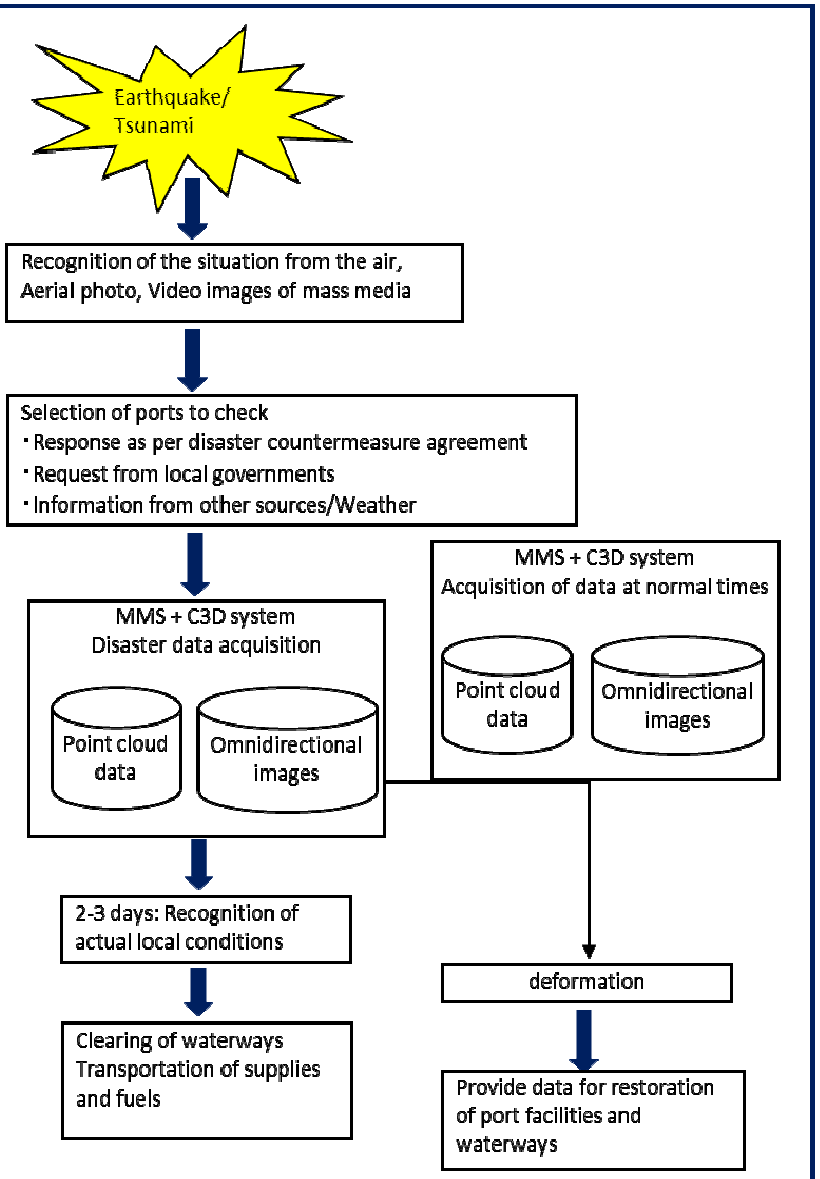

Figure.14. Flow of coast disaster prevention

\section{Acknowledgement}

We express our sincere gratitude to Prof. Tomoyuki Takahashi of Kansai University who gave us guidance on how to use the system not only at the time of disaster but also at normal times and get ready for the Nankai Trough Earthquake. We also thank Osaka Port Authority who granted us using Kishiwada Port for the test.

\section{REFERENCES}

Megumi Koizumi, 2012,ISPRS_2012, I/5: Integrated Systems for Sensor Georeferencing and Navigation,Application," Mobile Mapping for Damage survey after Great east Japan earthquake" 